\title{
Mulheres líderes em Educação. Da Baixada Fluminense para o
}

\section{mundo ${ }^{1}$}

\section{Woman Leaders in Education. From Baixada Fluminense to the}

\section{World}

\author{
Rosangela Malachias ${ }^{2}$
}

Submetido em 2 de novembro e aprovado em $1^{\circ}$ de dezembro de 2018.

Resumo: O artigo descreve reflexivamente as etapas concluídas e bem sucedidas do Projeto de Pesquisa e Extensão, iniciado em 2015 na Universidade do Estado do Rio de Janeiro, campus FEBF - Faculdade de Educação da Baixada Fluminense em Duque de Caxias, RJ, Brasil. A narrativa transita entre pessoalidade e impessoalidade compatíveis ao deslocamento identitário (HALL) da autora, que também é uma mulher negra, docente em uma universidade pública brasileira, protagonista e mediadora das ações construídas coletivamente com estudantes. A autodefinição e a autoavaliação (COLLINS) tem sido uma característica de pesquisas produzidas por e sobre mulheres negras.

Palavras-chave: Mulheres Negras. Líderes. Educação. Educomunicação. Diálogos.

Abstract: The article describes the successful stages of the Research and Extension Project started in 2015 at the Rio de Janeiro State University (UERJ), School of Education from Baixada Fluminense (FEBF) in Duque de Caxias, RJ, Brazil. The narrative transitions between personal and impersonal styles that compatible with the author's displacement (HALL) as a black woman, a teacher at a Brazilian public university and a protagonist and mediator of the actions constructed collectively with students. Self-definition and self-evaluation (COLLINS) has been a feature of research produced by and about black women.

Keywords: Black Women. Leaders. Education. Educommunication. Dialogues.

\section{Cultura Local - Baixada Fluminense, RJ, Brasil e a FEBF}

Os municípios que compõem a Baixada Fluminense são: Belford Roxo, Duque de Caxias, Guapimirim, Itaguaí, Japeri, Magé, Mesquita, Nilópolis, Nova Iguaçu, Paracambi, Queimados, São João de Meriti e Seropédica. A região está localizada ao norte do município do Rio de Janeiro, entre o litoral e a Serra do Mar. 


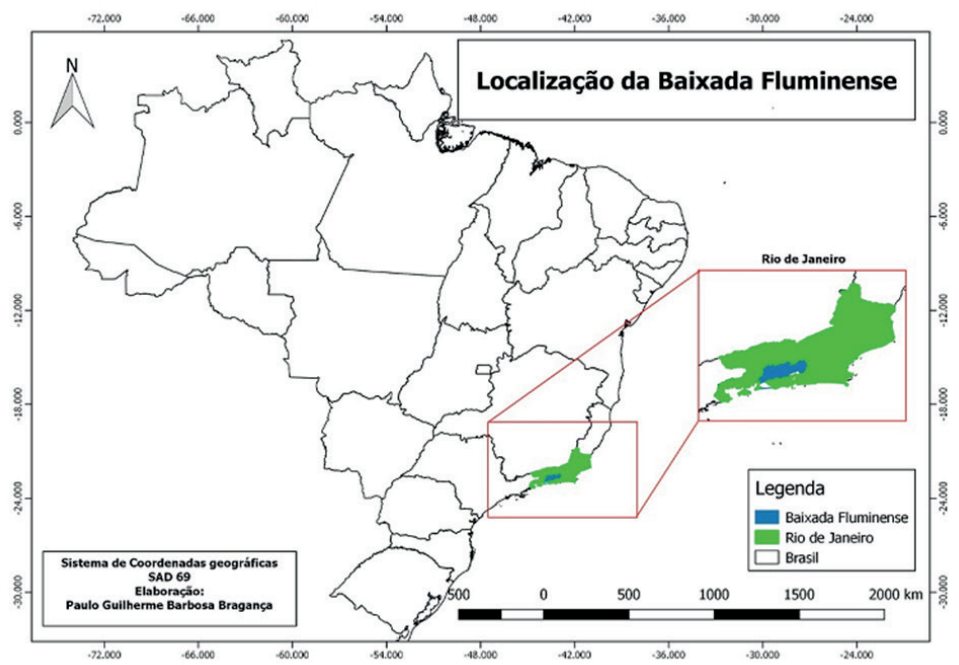

Fig. 1

No período escravista (1500-1888) a região ficou conhecida como Recôncavo da Guanabara sendo um importante polo na fabricação de alimentos. No século dezenove, a partir de 1850, a despeito da proibição do tráfico de escravizados, o porto de Magé permaneceu como centro do desembarque ilegal de milhões de africanos. No século vinte o Recôncavo passa a ser denominado de Baixada Fluminense e no período da ditadura militar registra aumento da violência e ausência do poder público (IPAHB, 2007). Os municípios situados na região metropolitana da cidade do Rio de Janeiro caracterizam-se por abrigar trabalhadores e diferentes movimentos ${ }^{3}$ organizados nas esferas da cultura, da educação e da comunicação pela defesa de direitos.

A UERJ - Universidade do Estado do Rio de Janeiro possui vários campi em diferentes cidades. A FEBF - Faculdade de Educação da Baixada Fluminense está situada em Duque de Caxias, município mais populoso da região e o terceiro ${ }^{4}$ mais populoso do estado com 882.729 habitantes. A FEBF coloca-se como polo produtor e mediador do conhecimento das periferias urbanas primando por perspectivas descolonizadoras. 
do Instituto de Educação Governador Roberto Silveira (IEGRS) uma escola de referência na formação de professores na região da Baixada Fluminense. (...) a Reforma do Ensino Superior (1968), a Reforma do Ensino de 1o. e 2o. Graus (1971), assim como a fusão dos Estados do Rio de Janeiro e a Guanabara (1974) geraram transformações de impacto no papel do Instituto de Educação: em 1966, por autorização do Conselho Estadual de Educação-RJ, teve inicio nesse Instituto o Curso de Formação de Professores para o Ensino Normal (CFPEN). Em 1971, o CFPEN passa a ser denominado Curso de Pedagogia, tendo seus diplomas chancelados pela então Universidade Federal Fluminense - UFF. Apos a fusão, em 1975, o Curso de Pedagogia se desvincula da UFF, mantendose vinculado a Secretaria de Estado de Educação. E somente em 1982, o Curso de Pedagogia do Instituto de Educação é incorporado a UERJ (...). No sentido de se preservar a necessária autonomia de suas atividades formativas, em 1988, a Faculdade de Educação da Baixada Fluminense - FEBF, Unidade Acadêmica da UERJ é finalmente criada através da Resolução 548/88. (...) a partir de 1998, em função de acordos firmados entre o Estado do Rio de Janeiro e a Prefeitura de Duque de Caxias, a FEBF se transfere em definitivo para o CIEP-090, localizado no bairro da Vila São Luiz, onde funciona ate hoje (...). ${ }^{5}$

\section{O Projeto - fase 1 / Contexto.}

Como docente recém-contratada por concurso ${ }^{6}$ público da UERJ, em junho de 2015, fui designada para lecionar quatro disciplinas - Cultura entre o Local e o Global (GLG/I-II-III-IV). As respectivas ementas propiciaram leituras, pesquisa e apresentação de seminários transdisciplinares. Em agosto de 2015, como membro de um grupo de scholars denominado WLE - Women Leading Education ${ }^{7}$ participei, na Nova Zelândia, da 5th WLE Conference e lá apresentei a candidatura da UERJ-FEBF como sede da 6th WLE Conference, a ser realizada em 2017. O Brasil foi aceito por unanimidade vencendo duas outras candidaturas (Reino Unido e Paquistão). De volta ao Rio de Janeiro, redigi o projeto de pesquisa e extensão, tema deste artigo, com ênfase na organização deste evento científico.

Além da necessária busca por parcerias priorizando instituições públicas de Duque de Caxias, a docência (ainda em fase probatória) fez-me atentar para a necessária formação do corpo discente. Neste sentido buscamos: (1) Preparar/formar estudantes para a participação ativa em eventos científicos internacionais. (2) Realizar pesquisas e ações educativas sobre Educação internacional, com ênfase no Gênero - status das meninas 
e mulheres. (3) Compartilhar pesquisas, habilidades, experiências e perspectivas locais e internacionais enfatizando abordagens interseccionais de classe, raça/etnia, gênero e geração. (4) Consolidar parcerias institucionais que visem a pesquisa, difusão e extensão. (5) Propiciar o desenvolvimento de repertórios culturais sobre a Baixada Fluminense para difusão e desenvolvimento local, regional e global.

De 2015 a 2016, o projeto transcorreu no âmbito das disciplinas semestrais GLG/I-II-III-IV. Neste período, a crise econômica nacional e escândalos de corrupção no governo do estado do Rio de Janeiro geraram interrupções no calendário da UERJ decorrentes da falta de repasse governamental das verbas de custeio, bem como o não pagamento dos salários de docentes, técnicos e bolsas dos(as) estudantes. As paralisações e greves afetaram algumas ações do projeto, que foi contemplado com apenas uma bolsa de estudos, dentre as quatro solicitadas.

Com a utilização das mídias digitais instigamos as/os estudantes a criarem conteúdos e realizamos uma votação pela internet (maio de 2016) para a escolha do tema central da Conferência Internacional. Votaram a Comunidade FEBF, composta por estudantes, docentes, funcionários; as pesquisadoras internacionais do grupo WLE. O slogan "Das Periferias aos Centros/From Margins to Centers" foi o vencedor e tornandose chave para a chamada de abstracts/resumos e artigos.

\section{Fase 2 - Pesquisa: Cultura: entre o Local e o Global}

As/os jovens estudantes de graduação, matriculadas(os) nas quatro disciplinas CLG (I-II-III-IV) foram instigadas(os) a promoverem pesquisas, que priorizassem a Cultura Local da Baixada Fluminense e a sua relação com mulheres líderes em educação de Duque de Caxias e das outras cidades vizinhas. A contextualização dos trabalhos deveria inserir perspectivas interseccionais de classe, gênero, raça e etnia.

(...) poverty can create the conditions that give rise to the immediate risk factors for violence involving youth. When racism, education difficulties, immigration settlement issues or mental illness or family stresses from poverty itself are added, these risk factors can even more easily be created (THE REVIEW OF ROOTS OF YOUTH VIOLENCE, 2008, 66) ${ }^{8}$. 
A avaliação final obedeceria à praxe institucional, ou seja, todas(os) estudantes precisam alcançar nota/score para aprovação na disciplina; porém aquelas(es) cujos temas fossem adequados à 6 th WLE Conference seriam convidadas(os) a participar do evento, que já estava em fase de organização, no primeiro dia da programação (23-julho-2017), para a apresentação de posters. Explicamos o quanto esta visibilidade seria uma oportunidade às/aos conferencistas de outras localidades, do Brasil e do exterior, de conhecerem um pouco da produção teórica e prática da UERJ-FEBF.

Esta ação não foi fácil, pois esbarrou na baixa autoestima das/os jovens residentes na Baixada Fluminense, que não viam a si mesmas(os) como capazes de participar de um evento de tamanha relevância e, com o agravante de desconhecerem indivíduos e espaços culturais, artísticos e educativos merecedores de atenção como sujeitos/objetos de pesquisa.

Dentre trinta trabalhos realizados por equipes de três turmas (manhã - 1 e noite - 2) para avaliação obrigatória de cada estudante identifiquei 12 temas relevantes para apresentação na 6th WLE Conference-Brazil, agendada para julho de 2017, pois referiam a mulheres que desempenham cotidianamente o papel de liderança educacional e cultural. Porém, apesar dessa avaliação positiva e do incentivo oferecido aos estudantes que se inscrevessem no evento, como a gratuidade da taxa de inscrição e da impressão de banners, somente quatro equipes (totalizando 10 pessoas) e três estudantes com trabalhos individuais se dispuseram a participar da conferência. Portanto, apenas seis temas (dois do curso de Geografia e quatro da Pedagogia) foram apresentados pelas estudantes da FEBF no evento científico internacional sendo 12 mulheres ( 9 negras; 3 brancas) e 1 homem (branco).

\begin{tabular}{|c|c|c|c|c|c|c|}
\hline $\begin{array}{c}\text { Total de } \\
\text { trabalhos } \\
\text { CLG } \\
(2016)\end{array}$ & $\begin{array}{c}\text { Trabalhos } \\
\text { aptos(*) } \\
\text { para apre- } \\
\text { sentação na } \\
\text { 6WLE. }\end{array}$ & $\begin{array}{c}\text { Total de } \\
\text { Trabalhos } \\
\text { de es- } \\
\text { tudantes da } \\
\text { FEBF na } \\
\text { 6th WLE. }\end{array}$ & $\begin{array}{c}\text { Estudantes } \\
\text { Mulheres } \\
\text { Negras } \\
\text { Expositoras }\end{array}$ & $\begin{array}{c}\text { Estudantes } \\
\text { Mulheres } \\
\text { Brancas } \\
\text { Expositoras }\end{array}$ & $\begin{array}{c}\text { Estudantes } \\
\text { Homens } \\
\text { Negros } \\
\text { Expositores }\end{array}$ & $\begin{array}{c}\text { Estudantes } \\
\text { Homens } \\
\text { Brancos } \\
\text { Expositores }\end{array}$ \\
\hline 30 & 12 & 6 & 9 & 3 & 0 & 1 \\
\hline
\end{tabular}

(*) Referiam a questões de liderança, gênero, educação e cultura.

Fig. 2 
Embora a Baixada Fluminense registre altos índices de violência, pobreza, falta de saneamento básico e desigualdade socioeconômica, a região também registra uma ativa participação cultural de organizações não governamentais, associações de artesãs, coletivos juvenis e cineclubes com produção sistemática e internacionalmente conhecida. Ainda assim, na mídia prevalece o discurso redutor a estereotipias ligadas à pobreza e à violência. Por isso, estudos, pesquisas e ações práticas que possam descolonizar mentalidades preconceituosas e representações negativas sobre a Baixada Fluminense (BF) são mais que necessárias.

Neste sentido, as quatro disciplinas Cultura entre o Local e o Global (I-II-III e IV) foram espaços de reflexão teórica sobre a multiplicidade conceitual de cultura (GEERTZ; LARAIA; CANCLINI) e a sua transdisciplinaridade (D’AMBRÓSIO; MORIN) como estímulo ao desempenho crítico da(o) Pedagoga(o) frente a um mundo globalizado pelas tecnologias da informação e desigual no que tange ao acesso de direitos sociais e econômicos.

A formação de jovens pedagogas(os) na Baixada Fluminense precisa considerar a importância da contextualização histórica, geográfica e cultural da região e de como a violência, principalmente a que se relaciona à juventude, pode ser prevenida por ações educativas e educomunicativas. Cabe dizer que os dados dos Mapas da Violência (2010 a 2014) publicados pelo Ministério da Justiça informam que, no Brasil, “os jovens negros são as vítimas preferenciais das mortes por arma de fogo".

A baixa auto estima entre as/os estudantes residentes na Baixada Fluminense não é fenômeno isolado ou restrito. Nas referências utilizadas em aula descobrimos que, em Ontário, Canadá, os jovens mais propícios a ingressar na violência são aqueles que; "tem um profundo sentimento de alienação e baixa autoestima; impulsividade e pouca empatia para com os outros; não vivenciam a noção de pertencimento; sentem-se oprimidos, reprimidos, sem escuta por parte da família e sociedade; não têm esperança”. (ROOTS OF YOUTH VIOLENCE, 2008, 19) ${ }^{9}$

De outubro a novembro de 2016, as equipes (com o máximo de cinco pessoas) tiveram a liberdade de escolher os seus temas geradores e, dentre dezenas, destacamos quatro cujas personagens, definidas pelas equipes, são mulheres que nas suas escolhas pessoais e profissionais enfrentaram barreiras e optaram pela educação como um caminho a seguir. 
Título: Dona Luana: Liderança da Instituição Afrocultural Ojuobá Axé 32 anos de História/Title: Lady Luana: Leadership of the Afro Cultural Institution Ojuobá Axé - 32 years of history. ${ }^{10}$ Dona Luana saiu do estado da Bahia rumo ao Rio de Janeiro, Duque de Caxias, para fugir da miséria e da violência doméstica. Dedicou-se por anos à realização de um sonho: abrir uma instituição para atender mulheres que vivenciavam a violência e crianças carentes. A organização cresce e nos anos 1990 recebe a visita de Nelson Mandela quando o líder veio ao Brasil. Há 32 anos, o Instituto Afro Cultural Ojuobá Axé realiza projetos culturais e de cidadania atendendo centenas de pessoas na cidade de Duque de Caxias tornando-se referência social na Baixada Fluminense.

Título: Mulheres Protagonistas na Política: a representatividade da mulher na política na Baixada Fluminense - Duque de Caxias/Title: Protagonist Women in Politics: The representativeness of women in politics in the Baixada Fluminense-Duque de Caxias. ${ }^{11}$ O trabalho focou a trajetória das mulheres candidatas, eleitas ou empossadas a cargos políticos no governo de Duque de Caxias. Em comum dividem um dado curioso, cultural e significativo para a compreensão do papel da mulher na sociedade brasileira (e talvez em outros contextos internacionais) - a ligação por apadrinhamento político; amizade; namoro, casamento - com um homem considerado poderoso e, por isso, o responsável pela indicação dessas mulheres. Outro fato interessante observado pelas estudantes pesquisadoras referese à competência e escolaridade elevada (pós-graduação) das mulheres políticas que, ao mostrarem competência e adquirirem formação superior aos seus pares - homens na política - enfrentaram boicotes retaliações e a separação no casamento.

Título: Educação Não formal: O Protagonismo de mulheres negras jovens no YouTube/Title: Non-Formal Education: The Protagonism of Young Black Women in the YouTube. ${ }^{12}$ O YouTube é a plataforma que amplia falas locais tornando-as globais, a despeito das barreiras linguísticas. Os acessos vêm dos vários cantos do mundo e a agenda do respeito à diversidade étnica e igualdade de gênero se amplia. É no espaço virtual da internet, que jovens negras - sem representatividade na mídia hegemônica - criaram seus canais de comunicação para propagar seu pensamento feminista e estético.

Título: Mate com Angu: formação de identidades, silenciamentos, produção cultural em Duque de Caxias/ Title: Mate with Angu: Identities, Cultural Prodution and 
Silence. ${ }^{13}$ A equipe elegeu o espaço cultural Cineclube Mate com Angu, localizado no centro de Duque de Caxias, como local propiciador de uma valorização de identidades regionais, de gênero, raça de seus frequentadores. O nome Mate com Angu refere ao lanche distribuído a crianças carentes (chá e mingau de fubá) que frequentavam a Escola Regional de Meriti, fundada na década de 1920 por Armanda Álvaro Alberto (18921974), a professora que idealizou a merenda escolar no Brasil.

A 6th WLE Conference - From Margins to Centers - no Brasil - tornou-se MLE - Mulheres Líderes em Educação. Das Periferias aos Centros. O encontro totalizou a presença de 94 pessoas; 55 papers e participantes de 12 países - Austrália, Brasil, Estados Unidos, Gana, Índia, Filipinas, Nigéria, Nova Zelândia, Paquistão, Quênia, Reino Unido. Destacamos abaixo os temas que aludiram às Mulheres Negras, inscritos na "Sessão 4 Gênero - Liderança e Africanidades/Leadership, Gender and Africanness" (ver tabela 2) por conferencistas estrangeiras e brasileiras

\section{PROGRAMAÇÃO}

6th Women Leading Education Conference - Brazil. From Margins to Centers. Mulheres Líderes em Educação. Das Periferias aos Centros.

23-Julho-2018 - Abertura Solene. / Sessão de Posters - Estudantes da FEBF./ Dia Cutural.

\begin{tabular}{|c|c|c|}
\hline 24-Julho-2017 & 25-Julho-2017 & 26-Julho-2017 \\
\hline $\begin{array}{l}\text { SESSÃO 1- Diversidade } \\
\text { Cultural - Direitos Humanos } \\
\text { e Povos Tradicionais. Human } \\
\text { Rights - Cultural Diversity } \\
\text { and Traditional Peoples }\end{array}$ & $\begin{array}{l}\text { SESSÃO } 4 \text { - Gênero, Lider- } \\
\text { ança, Africanidades. Leader- } \\
\text { ship, Gender, Africanness }\end{array}$ & $\begin{array}{c}\text { SESSÃO } 7 \text { - Violência e } \\
\text { Subjetividades - Sexuali- } \\
\text { dade e Gênero. Violence and } \\
\text { Subjectivities and Violence - } \\
\text { Sexuality and Gender. }\end{array}$ \\
\hline $\begin{array}{c}\text { SESSÃO } 2 \text { - Gênero e } \\
\text { Liderança - Ser uma Líder na } \\
\text { Sociedade / Educação Formal } \\
\text { - (A). } \\
\text { Gender and Leadership } \\
\text { - Being Leaders in Society - } \\
\text { Formal Education - (A) }\end{array}$ & $\begin{array}{c}\text { SESSÃO } 5 \text { - Gênero e } \\
\text { Liderança - Educação Não } \\
\text { Formal - Parcerias Institu- } \\
\text { cionais. Partnership Gender } \\
\text { and Leadership - Non-Formal } \\
\text { Education -Institutional } \\
\text { Partnership. }\end{array}$ & $\begin{array}{c}\text { SESSÃO } 8 \text { - Mantendo acesa } \\
\text { a chama da Justiça Social / } \\
\text { WLE/MLE Fazendo História. } \\
\text { Fanning the Flame for Social } \\
\text { Justice - WLE Making His- } \\
\text { tory }\end{array}$ \\
\hline
\end{tabular}




\begin{tabular}{|c|c|c|}
\hline SESSÃO 3 - Educação e & SESSÃO 6 - Gênero e & SESSÃO 9 - Gênero e Lider- \\
Deficiência. Education and & Liderança - Ser uma Líder na & ança - Ser uma Líder na So- \\
Disability & Sociedade / Educação Formal / Educação Formal \\
& (B) - Gender and Leadership & (C) - Gender and Leadership \\
& - Being Leaders in Society - & - Being Leaders in Society - \\
& Formal Education (B) & Formal Education (C) \\
\hline
\end{tabular}

Fig. 3

\section{Mulheres Negras: narrativas locais e globais nos Abstracts/Resumos e Artigos}

Os temas sobre Mulheres Negras que as pesquisadoras conferencistas de outros países apresentaram na 6th WLE/MLE no Brasil foram: Rwandan Women in Educational Leadership: Progress, Successes, and Challenges ${ }^{14}$; Lessons From Pioneers: A Case Study of the M.A. in Peace Studies \& Conflict Transformation at the University of Rwanda ${ }^{15}$; Black women's intellectual and leadership development in higher education: An autoethnographic inquiry ${ }^{16}$; Missing in Action: A Critical Study of the Absence of Black Female Science Teachers ${ }^{17}$; Enduring the Experience: The Development of a Black Teacher Leader at a Predominantly White, Elite, Independent School ${ }^{18}$;

As conferencistas brasileiras também apresentaram resumos sobre Mulheres Negras. Os títulos: O Protagonismo das Mulheres Negras em Ribeirão Preto, SP ${ }^{19}$; Irmandade de Nossa Senhora Aparecida e São Benedito do Lauzane Paulista - SP ${ }^{20}$; O Protagonismo feminino nas religiões de matrizes africanas no Brasil ${ }^{21}$; Professora, Mulher Negra e a Lei da Diversidade ${ }^{22}$.

Houve ainda trabalhos que fizeram análise das desigualdades de gênero e raça, a partir da forma como personagens femininas negras aparecem representadas nos espaços de poder - A Influência do Patriarcado junto às Mulheres de Comunidades Tradicionais do Território da Cidadania da Baixada Cuiabana, Mato Grosso ${ }^{23}$; na mídia educativa As Personagens Femininas dos Livros Paradidáticos "Tosco" e "Compreendendo Tosco": educação sobre gênero e identidade em questão ${ }^{24}$ e nos presídios - "Deixa eu ver como ficou" e a Etnografia Visual numa Penitenciária Feminina ${ }^{25}$.

$\mathrm{Na}$ primeira WLE Conference, em Roma, 2007 apresentei comunicação e posteriormente a publiquei como artigo intitulado Communicative Actions. Brazilian 
Women in Educational Leadership (MALACHIAS, 2009), no qual o quantitativo das mulheres brasileiras no ensino superior evidenciava a ausência de dados sobre cor/raça e etnia das mesmas. Este fato instigou-nos a apresentar uma cronologia dos Movimentos de Mulheres Negras no país.

A preocupação com o que consideramos necessário - representatividade das mulheres negras sem estereotipias - pauta o histórico pessoal desta autora e tem sido uma estratégia inclusiva dentro de uma universidade que, embora pública e a primeira ${ }^{26}$ do país a implantar o sistema de cotas raciais para estudantes, ainda carece de ampla diversidade étnico-racial em suas diferentes instâncias institucionais, leia-se docência e gestão.

Cada um desses temas e personagens evidenciam a universalidade e a especificidade na busca das mulheres negras por direitos. Ao reconhecermos os espaços locais das periferias ou globais das grandes cidades, múltiplas interpretações sobre a realidade das mulheres negras podem surgir. As especificidades contextualizadas histórica, econômica, social e geograficamente ampliam as interpretações e dinamizam possíveis soluções de problemas fundamentais como o racismo, o sexismo, a violência e a exclusão. Neste sentido, a socióloga Patricia Hill Collins nos respalda quando define a relevância do feminismo negro, composto pelos conceitos da "autodefinição" e "autoavaliação".

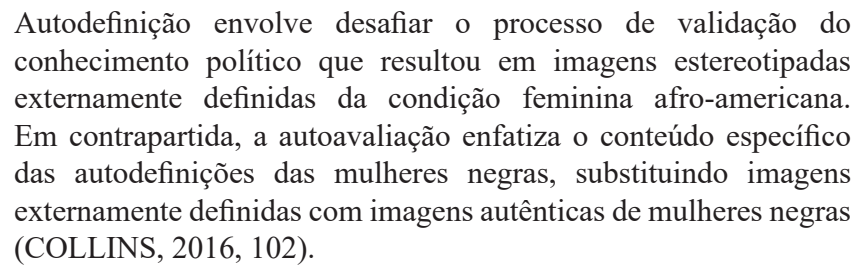

Desde a sua criação, o grupo internacional de scholars defende o direito intercontinental das mulheres à justiça social, ao acesso à educação e a mobilidade direcionada a cargos de liderança nos espaços/instituições educacionais. A justiça social está vinculada ao respeito aos direitos humanos. Para Gewirtz \& Cribb (2014) o conceito de justiça social é múltiplo e gera tensões em suas significações. Mas, salientam a relevância das concepções de Rawls, para quem a ideia de justiça distributiva é a conceituação corrente para justiça social sendo "o modo pelo qual as principais instituições [...] distribuem direitos e deveres fundamentais e determinam a distribuição de vantagens da 
cooperação social” (RAWLS: 1972, p.7). Outra autora mencionada por ambos é Nancy Fraser, que insere a ideia de justiça cultural compatível com as conceituações de Pierre Bourdier sobre capital cultural e capital social (GEWIRTZ \& CRIBB: 201, p. 129).

A aproximação de experiências profissionais propiciou o intercâmbio de narrativas pessoais vivenciadas em realidades socioculturais diferentes e, nas quais as relações sociais, políticas e culturais são pedagógicas. A vida segue e por isso, embora o projeto realizado para a organização da conferência tenha terminado - com o evento bem sucedido - a pesquisa prossegue focando novas e contínuas ações, principalmente aquelas que vislumbram o direito a uma vida digna, sem racismo, sexismo, violência.

\begin{abstract}
É no cotidiano do bairro, da casa, da escola, da empresa, das cidades, que estão materializados os efeitos da dominação e da exploração e da injustiça social. É aí onde a desigualdade se reproduz como parte da existência humana, mas é aí que os movimentos de lutas cotidianas, quase sempre invisíveis, tomam forma como parte dessa existência. É a partir daí que afloram as contradições que irão forjar, nos espaços da organização coletiva, a consciência do sujeito e as formas de resistência individual movidas pelo sentimento de injustiça, bem como os desejos de mudança (ÁVILA: 2009, p.63).
\end{abstract}

A produção de conhecimento exterioriza as contradições. A busca pela transformação e justiça social intercontinental do coletivo das mulheres é efetivamente uma atitude legítima, mas também está sujeita ao silenciamento e/ou a naturalização de estereotipias propagadas na esfera pessoal, que reificam as desigualdades. Neste sentido, a valorização das experiências individuais podem ter sim uma força coletiva e, no que se refere às mulheres negras, segundo Collins, a perspectiva singular das experiências coexiste com situações que serão compartilhadas pelas mulheres negras como grupo (COLLINS, 2016, 102).

\title{
Considerações Finais
}

A ação docente, por ser dinâmica, implica a mudança de conteúdos e disciplinas. O trabalho como coordenadora do AFRODIÁSPORAS ${ }^{27}$ - Núcleo de Pesquisas sobre Cultura Negra, Visualidades e Educação favorece a continuidade do projeto (agora visando a 7th WLE Conference, a ser realizada em Nottingham, UK). A produção de uma revista digital com artigos da 6th WLE; um filme com o resumo das falas; 
pôsteres: participações em congressos nacionais posteriores... são alguns produtos que o projeto propiciou.

No AFRODIÁSPORAS mantemos o trabalho de pesquisa e descobrimos um projeto extremamente interessante desenvolvido em Toronto, Canadá. Trata-se do the Black Experience Project, cuja pesquisa considera a "complexity and diversity of identities within the Black community in the Greater Toronto Area (GTA)". Acreditamos que esta experiência pode ser reelaborada, com as devidas considerações transculturais, na região da "GBF" (Grande Baixada Fluminense). A autora afroamericana Sarah Lightfoot confessa ${ }^{28}$ ter "inventado uma nova metodologia" (LIGHTFOOT, 2005, p.6) sob a influência de filósofos, novelistas, pesquisadores, artistas... Trata-se de um caminho descritivo que retrata as narrativas coletadas em ambientes escolares de forma a unir, com rigor empírico e etnográfico, a arte e a ciência. Este trajeto nos inspira e estimula a considerar, na concepção metodológica das entrevistas e na sua execução e compartilhamento, ocorrência da interface entre Educação e Comunicação, como campos que expõem a dinamicidade histórica favorecendo políticas de advocacy (LIBARDONI, 2007). As ações de advocacy identificam e formam lideranças - atores/sujeitos estratégicos - em processos educativos constantes.

Neste mosaico de aprendizado, autoras(es) brasileiros, canadenses, afroamericanos, latinoamericanos, africanos e asiáticos ampliam a nossa percepção de mundo. Porém, perseguimos respostas que sublinham o relativismo, mas que ainda assim pontuem a apreensão dos discursos expressos ou impressos pelas mulheres negras, sujeitos históricos do estudo. Neste sentido, entrevistadora e entrevistadas se autoavaliam (COLLINS, 2016) e constróem sua comunicação e significados políticos, culturais e simbólicos reconhecendo especificidades históricas, nas quais as relações de poder, ideologias, desigualdades impactam diretamente os ambientes educativos como a escola, a universidade e demais espaços não formais.

\section{Referências}

ÁVILA, MB - Vida cotidiana: um desafio político e teórico para o feminismo. In: Cadernos de Críticas Feminista. Ano III, No. 2 - dez. 2009, pp.44-79.

COLLINS, PH - Aprendendo com a outsider within: a significação sociológica do pen- 
samento feminista negro. Revista Sociedade e Estado - Volume 31 Número 1 Janeiro/Abril 2016. Disponível em <http://www.scielo.br/pdf/se/v31n1/0102-6992-se-31-01-00099. pdf $>$. Acesso em 15 de maio de 2017.

FALS BORDA, O. Aspectos teóricos da pesquisa participante: considerações sobre o significado e o papel da ciência na participação popular. In: Brandão, Carlos Rodrigues - Pesquisa Participante. São Paulo, Brasiliense, 1988.

FREIRE, Paulo - Extensão ou Comunicação? Rio de Janeiro, Paz e Terra, 1980.

GADOTTI, Moacir - Convite à Leitura de Paulo Freire. São Paulo, Editora Scipione, 1991.

GEWIRTZ, Sharon \& CRIBB, Alan - Concepções plurais de Justiça Social: implicações para a sociologia das políticas. In: Políticas Educacionais: questões e dilemas. Stephen J. Ball \& Jefferson Mainardes (Orgs.). São Paulo, Cortez, 2011. [Tradução de Plural conceptions pf social justice: implications for policy sociology, publicado no Journal of Education Policy v.17, n.5, p.499-509, 2002. Verônica van Wilpe. Revisão técnica de Márcia dos Santos Ferreira e Jefferson Mainardes].

GOHN, Maria da Glória - Teoria dos Movimentos Sociais. Paradigmas clássicos e contemporâneos. São Paulo, Loyola, 1997.

GONZALEZ, Lélia e HASENBALG, Carlos A. - Lugar de Negro, Rio de Janeiro, Editora Marco Zero, 1982.

HALL, Stuart - Identidades na Pós Modernidade, Rio de Janeiro, DP\&A Editora, $1^{\mathrm{a}}$ edição em 1992 - 11 a edição em 2006, 102 pp.

IPAHB - Instituto de Pesquisa e de Análises Históricas da Baixada Fluminense - João Xavi, 09/8/2007. São João do Meriti, Rio de Janeiro - Disponível em < http://www. overmundo.com.br/guia/ipahb-instituto-de-pesquisa-e-analises-historicas-da-baixadafluminense> acesso em 08 de setembro de 2018.

LIBARDONI, M- Fundamentos Teóricos e Visão Estratégica da Advocacy. In: Revista Estudos Feministas. Capa > v. 8, n. 2 (2000) > Libardoni. [Acesso em setembro de 2015].

LIGHTFOOT, SL - Reflections on Portraiture: A Dialogue Between Art and Science. Published by http://www.sagepublications.edu 2005. Acessado em 21/11/2016.

MALACHIAS, R - Epistemologias Afrobrasileira e Afrocolombiana na Interface Comunicação e Educação. Anais do II Simpósio Internacional Pensar e Repensar a América Latina, outubro 2016. ISBN: 978-85-7205-159-0. Diponível em < https://sites. usp.br/prolam/wp-content/uploads/sites/35/2016/12/MALACHIAS_SP21-Anais-do-IISimp $\%$ C3\%B3sio-Internacional-Pensar-e-Repensar-a-Am\%C3\%A $\%$ rica-Latina.pdf> Acesso em 20 de janeiro de 2017.

MALACHIAS, R - Talking about Intersections of Gender, Race and Class in the Training of Public Teachers in São Paulo, Brazil. In: Women Leading Education across the Continents: Overcoming the Barriers. Editors Elizabeth C. Reily \& Quirin J Bauer. Nova York - Toronto, Rowman and Little Field, 2015. 
MALACHIAS, R - Communicative Actions. Brazilian Women in Educational Leadership. In: Women Leading Education Across the Continents - Sharing the Spirit, Fanning the Flame. Edited by Helen C. Sobehart foreword by Charles Dougherty. Lanham, New York, Torornto, Plymouth, UK, American Association of School Administrators, 2009, 230 pp.

SHÖN, Donald A. Educando o Profissional Reflexivo: um novo design para o ensino e a aprendizagem. Trad. Roberto Cataldo Costa. Porto Alegre: Artmed, 2000, 256p.

SILVA, PBG - "Chegou a hora de darmos a luz a nós mesmas": Situando-nos enquanto mulheres e negras. Cad. CEDES [online]. 1998, vol.19, n.45 [cited 2016-10-19], pp.723. Available from: <http://www.scielo.br/scielo.php?script=sci_arttext\&pid=S010132621998000200002\&lng=en\&nrm=iso>. ISSN 0101-3262. http://dx.doi.org/10.1590/ S0101-32621998000200002. Acesso em 15/10/2016.

WOMEN LEADING EDUCATION ACROSS THE CONTINENTS. Edited by Elizabeth C. Reilly \& Quirin J. Bauer foreward by Helen C. Sobehart. Rowman \& Littlefield, Lanham, Boulder, New York, Toronto, Plymouth, UK, 2015.

\section{Notas}

${ }^{1}$ Este trabalho foi parcialmente apresentado no V CEDUCE - V COLÓQUIO INTERNACIONAL EDUCAÇÃO, CIDADANIA E EXCLUSÃO de 28-30 de junho de 2018 na UFF - Universidade Federal Fluminense, Niterói, RJ.

2 Professora Adjunta da UERJ-FEBF - Universidade do Estado do Rio de Janeiro, Faculdade de Educação da Baixada Fluminense, Departamento de Ciências e Fundamentos da Educação, Duque de Caxias, RJ, Brasil. rosmalach@gmail.com

${ }^{3}$ Dentre vários citamos o Cineclube Mate com Angu (Duque de Caxias), a ong Oju Obá Axé (Duque de Caxias), a TV Maxambomba (Nova Iguaçu), a Rádio Comunitária Novos Rumos (Queimados), o Ponto de Cultura Lira de Ouro e o Movimento de Mulheres da Baixada (São João de Meriti), o Movimento de Trabalhadores Rurais Sem Terra de Nova Iguaçu, o Fórum Cultural da Baixada, o Pré-Vestibular para Negros e Carentes etc.

${ }^{4} \mathrm{O}$ primeiro é a cidade do Rio de Janeiro, com 6.520.266 habitantes; o segundo São Gonçalo, com 1.038.081 habitantes (dados do Instituto Brasileiro de Geografia e Estatística - 2015).

${ }^{5}$ Histórico da FEBF. Acessar mais detalhes no link - http://www.febf.uerj.br/site/?page_id=1003 [acesso em 19/Set./2018.

${ }^{6}$ Em 2015 e 2016 a UERJ abriu processo seletivo (após um longo período sem contratações). Na FEBF, o número de docentes negras/os cresceu de 1 (um) para 7 (sete) dentre 30 novos professores/as. Esta presença negra foi celebrada pelos/as estudantes negros/as da unidade.

${ }^{7}$ O grupo de scholars WLE - Women Leading Education (Mulheres Líderes em Educação) foi criado em 2006, nos Estados Unidos, por Helen Sobehart (na época reitora da Duquesne University, campus 1, na Filadelfia) e Charol Shakeshaft (docente da Virginia Commonwealth University, campus Virgínia). O WLE Group tem como lema a frase - Fanning the Flame for Social Justice / "A flama pela Justiça Social deve ser mantida acesa". As co-fundadoras uniram-se para pesquisar o desempenho de mulheres nas universidades norte-americanas e receberam apoio de Sharon Adams-Taylor, executiva da AASA - The School Superintendents Association (Associação de Superintendentes de Escolas), que também sugeriu a ampliação dessa pesquisa a outros países. Seguindo esses objetivos, a $1^{\text {a }}$ WLE Conference aconteceu no campus 2 da Duquesne University, situado em Roma, Itália, de 24 a 27 de julho de 2007. Desde 2007 foi estabelecido um calendário bianual de conferências relativamente pequenas, que reúnem cerca de 50 a 70 mulheres educadoras de diferentes países e áreas do conhecimento. A 2a WLE foi em Augsburg/Alemanha (2009); a 3a Volos/Grécia (2011); a 4a Apam/Gana (2013); a 5a Hamilton/Nova Zelândia (2015) e Duque de Caxias, RJ/Brasil (2017) sediou a 6a conferência, que teve o maior número de inscritos, 94 participantes. Os países que integram esta network são: África do Sul, Alemanha, Austrália, Canadá, China, Estados Unidos, Filipinas, Grécia, Índia, Reino Unido, Nova Zelândia, Paquistão, 
Tanzânia, Turquia, Uganda e o Brasil.

${ }^{8}$ Tradução livre: "a pobreza pode criar as condições que dão origem aos fatores de risco imediatos para a violência envolvendo os jovens. Quando o racismo, as dificuldades educacionais, os problemas de solução de imigração, as doenças mentais ou o estresse familiar causados pela pobreza são acrescentados, esses fatores de risco podem ser mais facilmente criados.

${ }^{9}$ Have a deep sense of alienation and low self-esteem; Have little empathy for others and suffer from impulsivity. Believe that they are oppressed, held down, unfairly treated and neither belong to nor have a stake in the broader society. Believe that they have no way to be heard through other channels. Have no sense of hope.

${ }^{10}$ Estudantes de Pedagogia FEBF - Ana Lúcia da Silva - Danielle Stumbo Barbier - Lucinete Silva de Oliveira Marielle Fatima da Silva Gomes.

${ }^{11}$ Estudantes de Pedagogia FEBF - Lohane Cristina de Castro Dantas - Maria Clara Moreira dos Santos - Isabelle Jesus Teixeira do Nascimento - Tatiane Pinheiro Cacimiro.

${ }_{12}$ Estudante de Pedagogia e ex-bolsista (Monitora) do projeto - Miriam Conceição Carvalho da Silva.

${ }^{13}$ Estudantes de Pedagogia FEBF - Angélica S. Pereira Ferreira - Carlinda C. Chaves Soares - Isis da S. Limas Damasio - Maissi de C. Julião Alves - Teresa C. Santos Balbino.

${ }^{14}$ Elizabeth Reilly - Chair and Professor, Loyola Marymount University;

${ }^{15}$ Sarah Doerrer - Ed.D. Candidate, Loyola Marymount University School of Education.

${ }^{16}$ Angela D. Coker - Visiting Professor John Hopkins University - School of Education.16

${ }_{17}$ Nadia Despensa - Loyola Marymount University School of Education.

${ }_{18}$ Tina B. Evans - Doctoral Student in the Educational Leadership for Social Justice Program

Loyola Marymount University

${ }_{19}$ Maria Helena Ramos de Oliveira, Universidade de São Paulo e Adria Maria Bezerra Ferreira, Casa da Mulher de Ribeirão Preto, SP.

${ }^{20}$ Zulmira Gomes Leite, Irmandade de Nossa Senhora Aparecida e São Benedito.

${ }^{21}$ José Geraldo Rocha - Prof. Titular Unigranrio.

${ }^{22}$ Lori Hack de Jesus e Waldinéia Antunes de Alcântara Ferreira - Universidade Federal do Mato Grosso.

${ }^{23}$ Lisanil da Conceição Patrocínio Pereira - Professora Universidade Federal do Mato Grosso.

${ }^{24}$ Diego Fernando Cunha Silva - Pesquisador do Mestrado e Maria de Lourdes da Silva, Profa. Adjunta - Universidade do Estado do Rio de Janeiro.

${ }_{25}$ Bárbara Copque - Profa. Adjunta da Universidade do Estado do Rio de Janeiro.

${ }^{26} \mathrm{Em} 2002$.

27 O Núcleo AFRODIÁSPORAS está vinculado ao PROMOVIDE - Programa Movimentos Sociais Diferenças e Educação da UERJ-FEBF.

${ }^{28}$ (...) I wanted to create a narrative that bridged the realms of science and art, merging the systematic and careful description of good ethnography with the evocative resonance of fine literature. (...)I found myself inventing a new methodology, one I eventually called "portraiture" as a way of reflecting its cross between art and science (...). (LIGHTFOOT, 2005, p.6). 